Scientific Journal of October 6 University

ISSN (Print): 2314-8640

ISSN (Electronic): 2356-8119

Published by October 6 University @ All Rights Reserved

Available online at: http:// sjou.journals.ekb.eg

Case Study
Citation: Abo Asil et al., (2016). Extraction and GC/MS and UPLC Detection of Diazinon Mixed with Malathion in Different Organs of Suicidal Death Human case. Sci. J. of Oct. 6 Univ.3(1), 7-13.

Copyright: (C) 2016 Abo Asil et al. This is an open-access article distributed under the terms of the Creative Commons Attribution License, which permits unrestricted use, distribution, and reproduction in any medium, provided the original author and source are credited.

\title{
Extraction and GC/MS and UPLC Detection of Diazinon Mixed with Malathion in Different Organs of Suicidal Death Human case
}

\author{
Mohammad Abo Asil ${ }^{1}$, Alaa Ibrahim ${ }^{1}$, *Mohammed A. Hussein ${ }^{2}$
}

\author{
${ }^{1}$ Drug analysis and toxins Expert- Drugs and Toxins labs - Forensic Medicine Authority, Cairo, Egypt. \\ ${ }^{2}$ Biochemistry Department, Faculty of Pharmacy, October $6^{\text {th }}$ University, October $6^{\text {th }}$ City, Egypt.
}

\section{Received: 22-11-2014/ Revised: 25-11-2014 / Accepted: 20-12-2014}

\begin{abstract}
Diazinon and Malathion are organophosphorus insecticides, widely used in some countries, for example Egypt. Suicidal death due to swallowing of any of them could occur. In our study, thin layer chromatography (TLC), gas chromatography/mass detection (GC/MS) and ultra performance liquid chromatography (UPLC) were used to detect Diazinon and Malathion in the stomach content, stomach wall, blood and the internal wash of the bottle that the victim drank from.
\end{abstract}

Key Words: Diazinon, Malathion, organophosphorus, insecticides and chromatography

\section{Introduction}

Organophosphorus pesticides are widely used in agriculture due to their high insecticidal activity ${ }^{(1)}$. They are toxic organic chemicals which can irreversibly inhibit acetylcholinesterase (AChE) which is essential for the function of the central nervous system ${ }^{(2,3)}$.

Diazinon (O,O- diethylO-(2- isopropyl -4- methyl6 - pyrimidyl) phosphorothioate, also known as "dimpylate" (Figure 1a), is an organophosphorus pesticide that has been widely used for many years in many countries. Diazinon is first registered in the United States in 1956 and used as an insecticide, acaricide, and nematicide ${ }^{(3)}$. Diazinon is a potent inhibitor to cholinesterases ${ }^{(4,5)}$, hence many accidental or suicidal intoxication cases have been reported ${ }^{(6,7)}$. Diazinon products are formulated as dusts, granules, liquids, concentrates, microencapsulations, wettable powders, seed dressings and impregnated materials. Malathion, or $\mathrm{O}, \mathrm{O}-$ dimethyl-S-(1,2 dicarbethoxyethyl) phosphorodithioate, is also an organophosphorus insecticide. It is frequently used for the control of insects on fruits and vegetables. Malathion has also been used to control mosquitoes, flies, miscellaneous household insects, animal parasites, and human head and body lice ${ }^{(8)}$.

Malathion (figure 1b) has a low mammalian toxicity. This is largely due to the presence of enzymes which are capable of hydrolyzing the carboxyl groups to yield the mono- and dicarboxylic acid analogs of Malathion.
Experimental studies and occupational exposure indicate that Malathion is only slightly toxic. Symptoms of organophosphate poisoning include defecation, urination, lacrimation, muscular twitching, and convulsions ${ }^{(9)}$. Although the convulsions may be tonic (limbs stretched and rigid), they are more likely to be clonic (rapid repetitive movement) in nature. The sequence of events leading up to death generally consist of inhibition of cholinesterase, acetylcholine accumulation, disruption of nerve function (centrally or peripherally), respiratory failure, and ultimately asphyxiation.

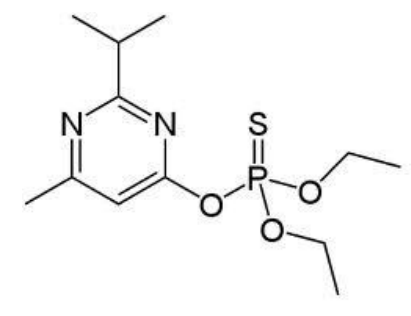

a) The chemical structure of Diazinon.

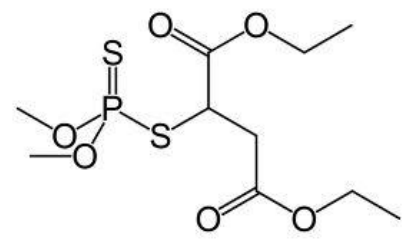

b) The chemical structure of Malathion.
Figure 1.

We report herein a case of suicide in which a victim drank a liquid labeled "Diazinon". In this case, initial screening was performed by thin-layer chromatography (TLC) and then confirmation using gas chromatography- mass spectrometry (GC-MS) and (UPLC/PDA) showed that the 
victim's stomach contents, the stomach wall and the liquid are drank contained Diazinon and Malathion.

\section{Case history}

A 19-year-old female was found dead with a 100$\mathrm{mL}$ bottle labeled " $60 \%$ Diazinon Emulsifiable Concentrate" beside her. There was a strong xylene-like or petroleum-like odour in the bottle. In the victim's mouth, there was the same odour as the liquid in the bottle, so at first this case was thought to be a normal suicidal case due to ingestion of the toxic pesticide, Diazinon. The actual dosage amount was unknown. According to the description on the label of the bottle, the bottle contents should have consisted of Diazinon.

\section{Autopsy findings}

No marked findings strongly suggesting organophosphorus poisoning were observed during the external examination. Pupil contraction was not obvious or relaxed.

Therefore, in order to clarify the cause of death, the victim's stomach contents, stomach wall, blood and the bottle contents were analyzed in detail.

\section{Materials and methods}

Diazinon, Malathion and all chemical are technical grade were purchased from ADWIA

Pharmaceuticals Co. (Cairo, Egypt).

\section{Extraction of samples}

The post-mortem blood sample, stomach content, kidney sample and liver sample were extracted with acetonitrile: acetone (9:1) (organic solvent) in clean centrifuge tubes. The stomach wall was washed with distilled water the homogenized and extracted with the same organic solvent. The bottle was internally washed with the same solvent. The organic extracts filtered through dried anhydrous sodium sulphate.

\section{Screening by TLC}

TLC analyses were performed using Merck Kieselgel 60F254 (Merck KGaA, Darmstadt, Germany) as a stationary phase, and a developing system of $n$-hexane-ethylacetate (7:3). The detecting reagents were Iodoplatinate and palidium chloride.

\section{GC-MS apparatus and conditions:}

All analyses were performed using a benchtop GCMS system which consisted of GC compartment 7890 A and Mass compartment 5975 C (inert MSD) with triple axis detector.

The oven temperature profile consisted of an initial temperature of $50^{\circ} \mathrm{C}$ ramped at $25^{\circ} \mathrm{C} / \mathrm{min}$ to $100{ }^{\circ} \mathrm{C}$ then $5{ }^{\circ} \mathrm{C} / \mathrm{min}$ to a final temperature of $300^{\circ} \mathrm{C}$ which was held for an additional $5 \mathrm{~min}$. The mass spectrometer was operated in the electron impact ionization mode with the electron energy set to 70 eV.

All samples were initially screened using a cyclical scan mode where $m / z$ values from 50 to 400 AMU were monitored in a period of $0.8 \mathrm{~s}$.

\section{UPLC/PDA apparatus and conditions:}

- Waters UPLC with Photodiode array detector and integrator, Acquity $\mathrm{H}$ class apparatus.

- The analytical column was waters C18 column UPLC, $150 \mathrm{~mm}$ x 2.1 I.D. $\mathrm{mm}$, particle size $1.7 \mu \mathrm{m}$, (Waters).

- Mobile Phase consisted of acetonitrile: water $0.1 \%$ o-phosphoric acid (70:30 v/v). The mobile phase was prepared freshly, filtered, sonicated before use and delivered at a flow rate of 0.2 $\mathrm{ml} / \mathrm{min}$.

\section{Screening by TLC}

The bottle wash, stomach content, stomach wall, blood, liver and kidney extracts were extracted with the organic solvent and analyzed by TLC. The results are showing that the bottle wash, stomach content, stomach wall, liver and kidney extracts are positive for Diazinon where the blood sample showed negative result for Diazinon. The bottle wash showed positive result for Malathion while the whole post-mortem sample produced negative malathion results.

\section{GC-MS analysis:}

Total ion chromatograms (TICs) of the organic solvent extracts from blood sample, stomach content, homogenized stomach wall, the bottle content, kidney sample, liver sample and authentic Diazinon and Malathion are shown in Figure (3) and (4), they were analyzed for the intact insecticides.

The stomach contents and liquid from the bottle showed almost the same chromatograms, in which Diazinon and Malathion were detected. Diazinon was the only insecticide detected in stomach wall, liver and kidney extracts, while in the blood sample nothing was detected.

The GC retention behavior was confirmed by comparison with that of the standard solutions of diazion and Malathion under identical operating conditions. The peak chromatogram of the bottle wash is shown in figure (5), which demonstrates that Diazinon was present in much higher concentration than Malathion, and that may explain the absence of Malathion from the stomach wall, liver and kidney extracts. 


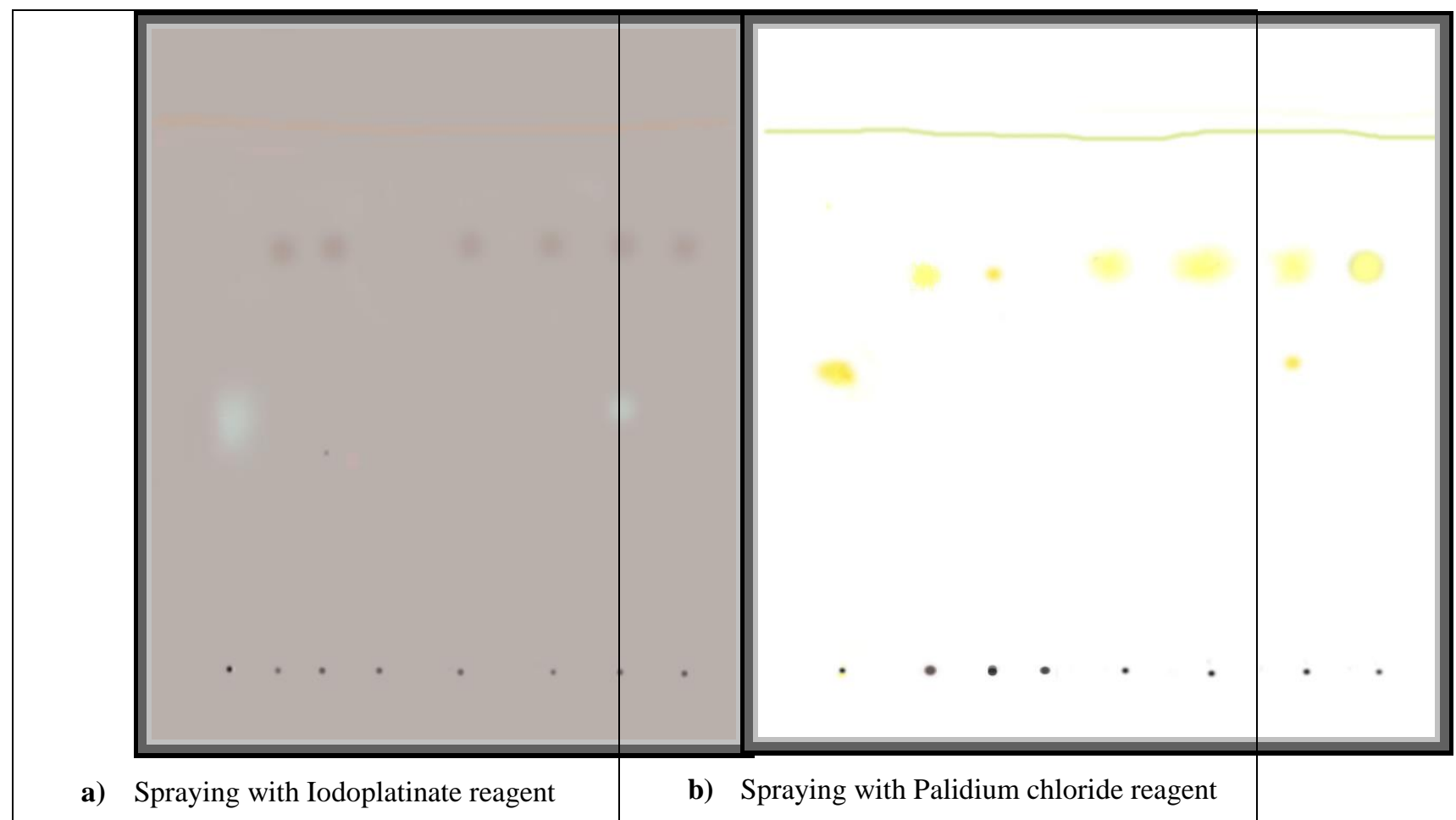

Figure 2: TLC of the extracted samples and the standards, starting from the right side; st. Diazinon, bottle wash, stomach content, stomach wall, blood, liver extract, kidney extract and Malathion.

The GC retention behavior was confirmed by comparison with that of the standard solutions of diazion and Malathion under identical operating conditions. The peak chromatogram of the bottle wash is shown in figure (5), which demonstrate that Diazinon was present in much higher concentration than Malathion, and that may explain the absence of Malathion from the stomach wall, liver and kidney extracts.

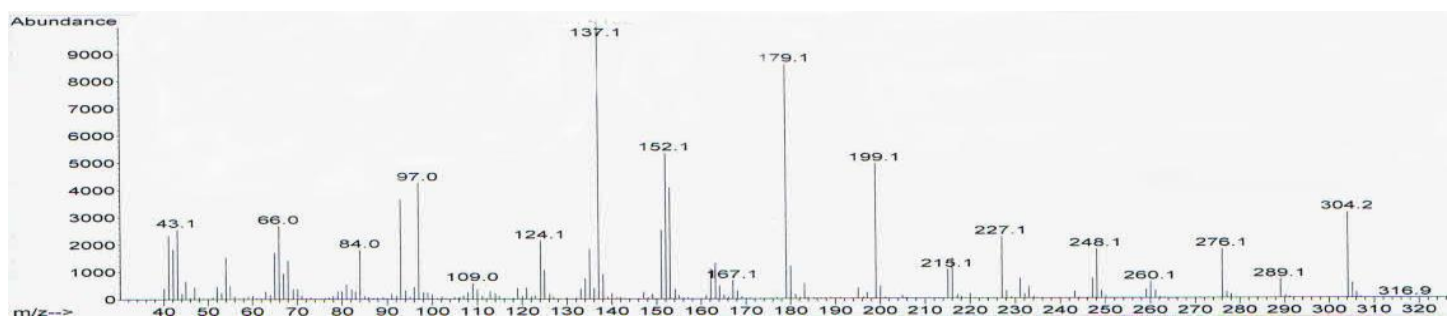

\section{St. Diazinon}

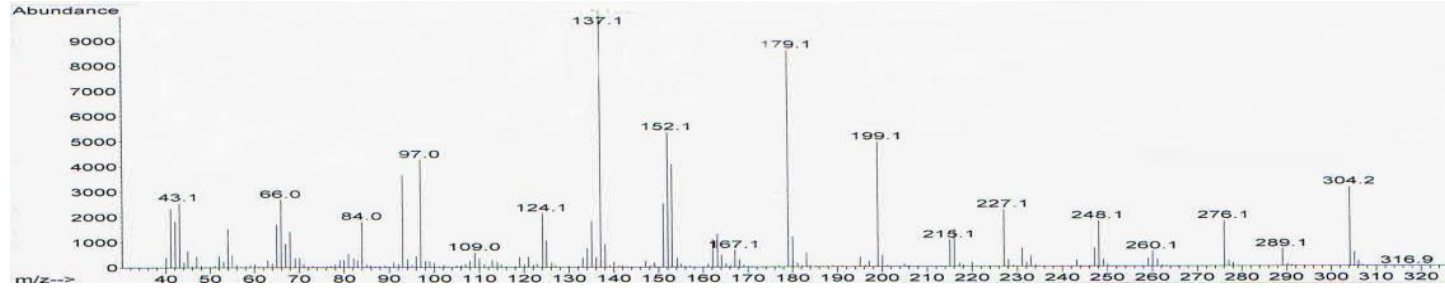

Diazinon from the bottle 


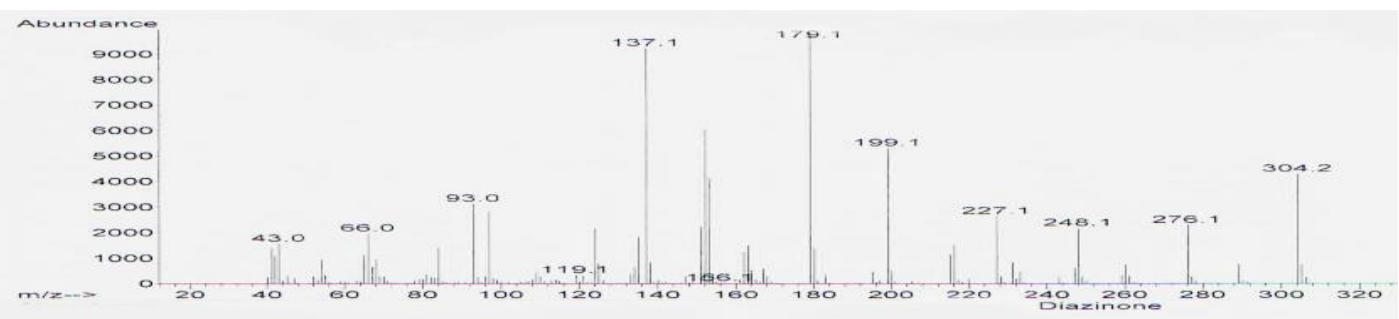

Diazinon in the stomach content

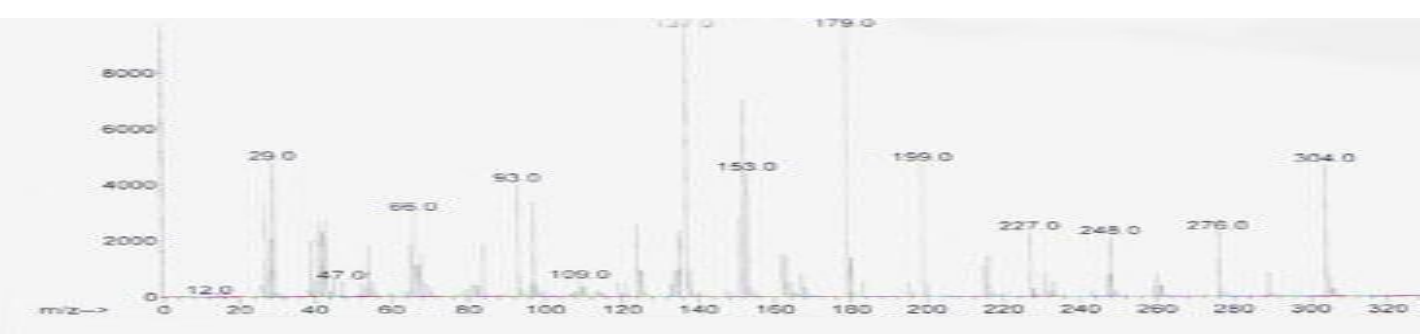

Diazinon in the stomach wall

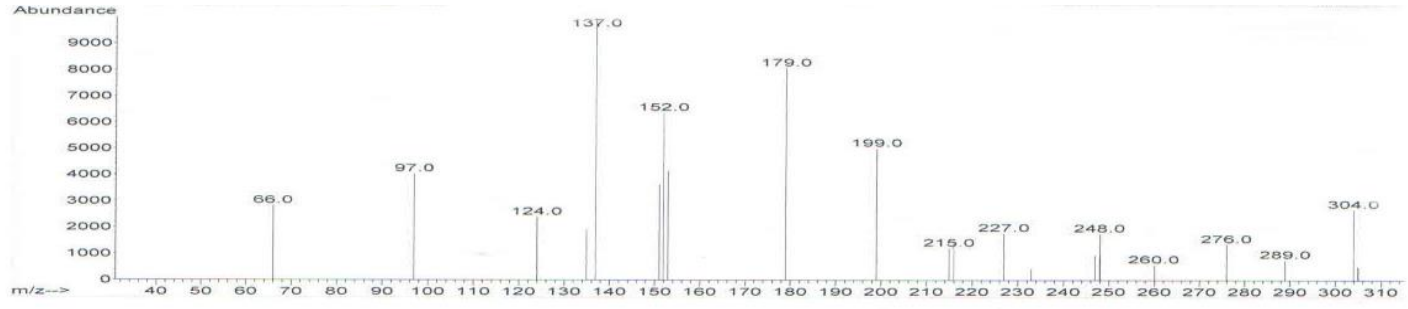

Diazinon in the liver

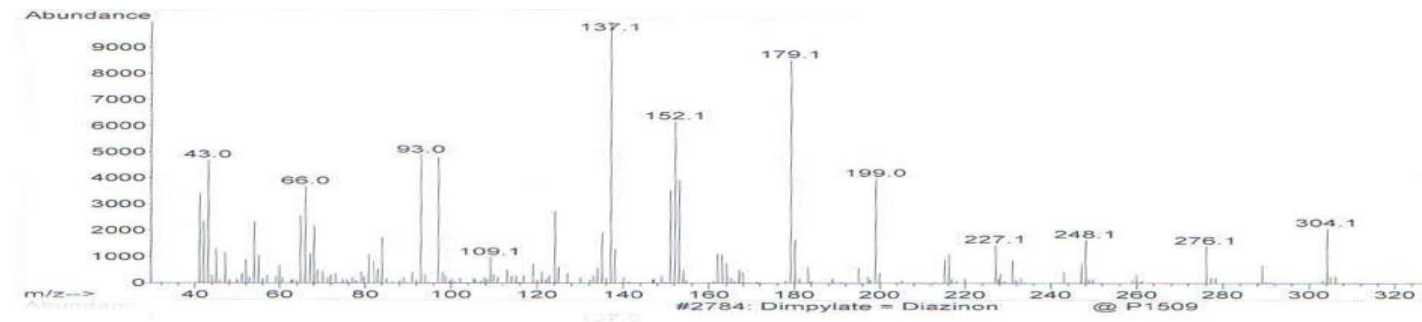

Diazinon in the kidney

Figure 3: the total ion chromatogram of Diazinon in the extracted samples

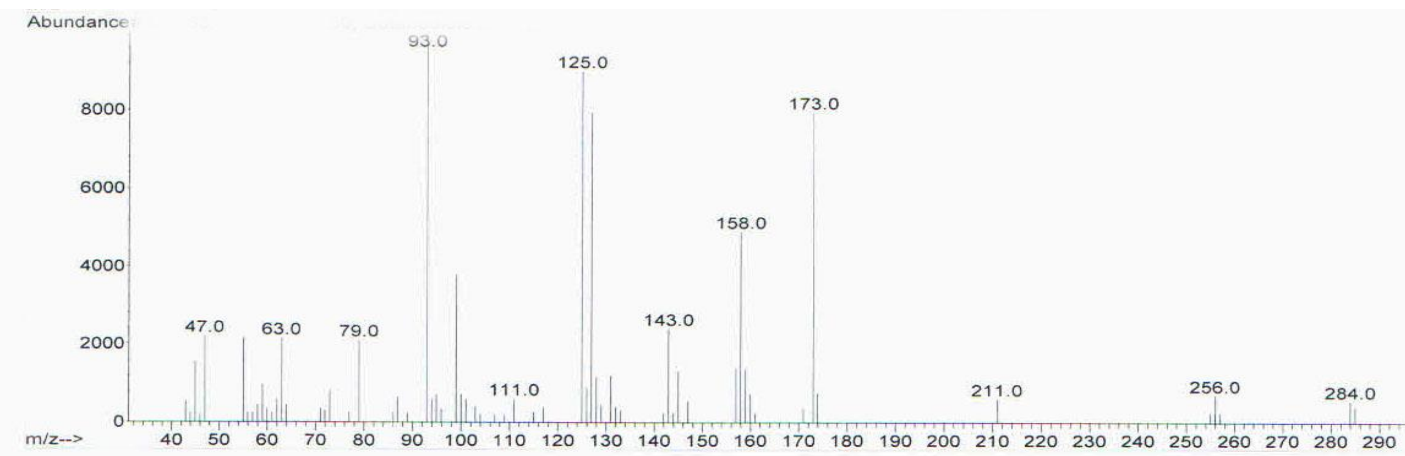

\section{Standard Malathion}




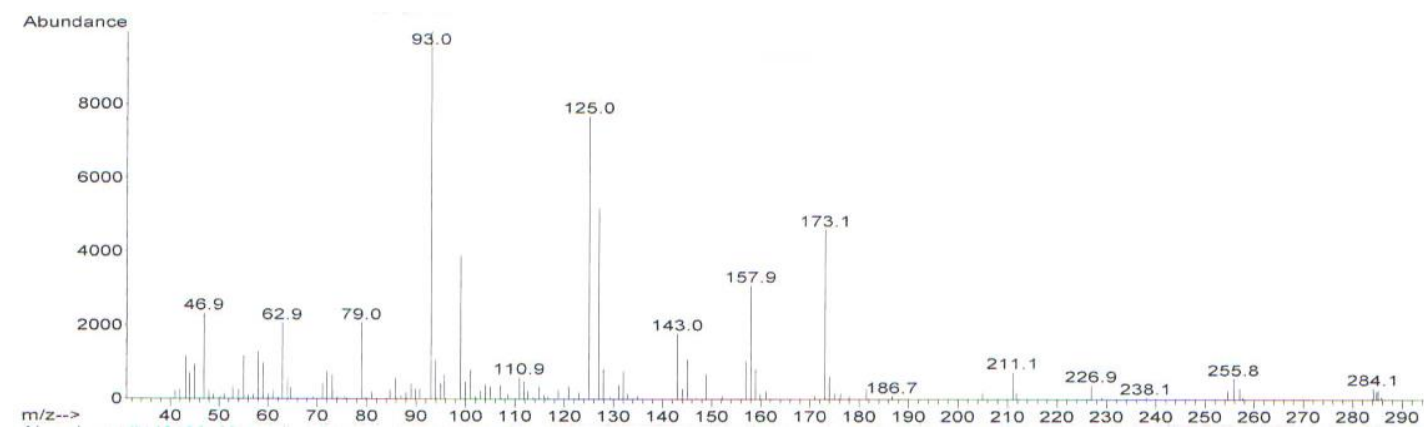

Malathion in the bottle wash

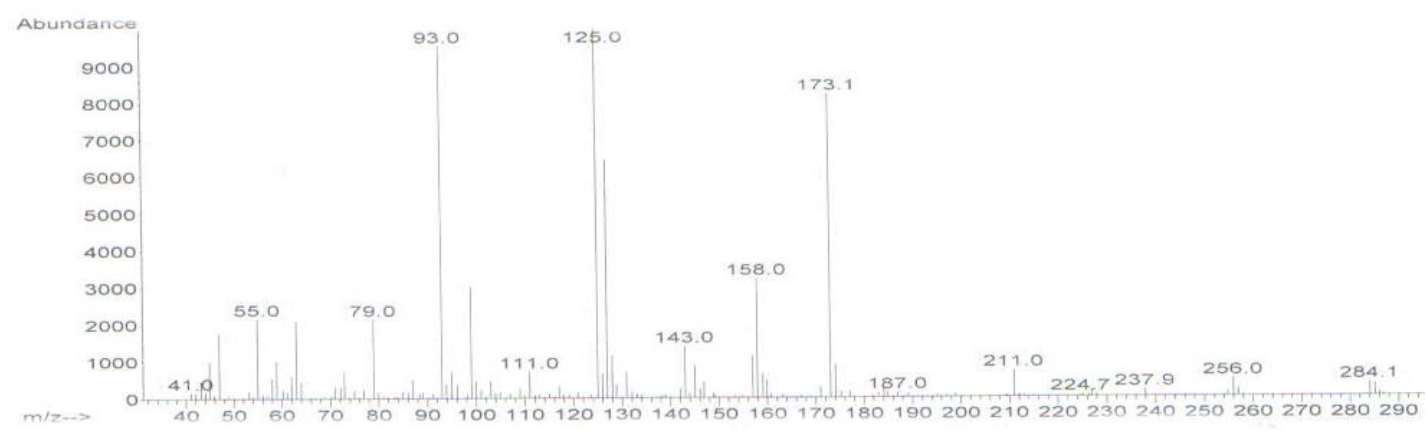

Malathion in the stomach content

Figure 4: the total ion chromatogram of Malathion in the extracted samples.

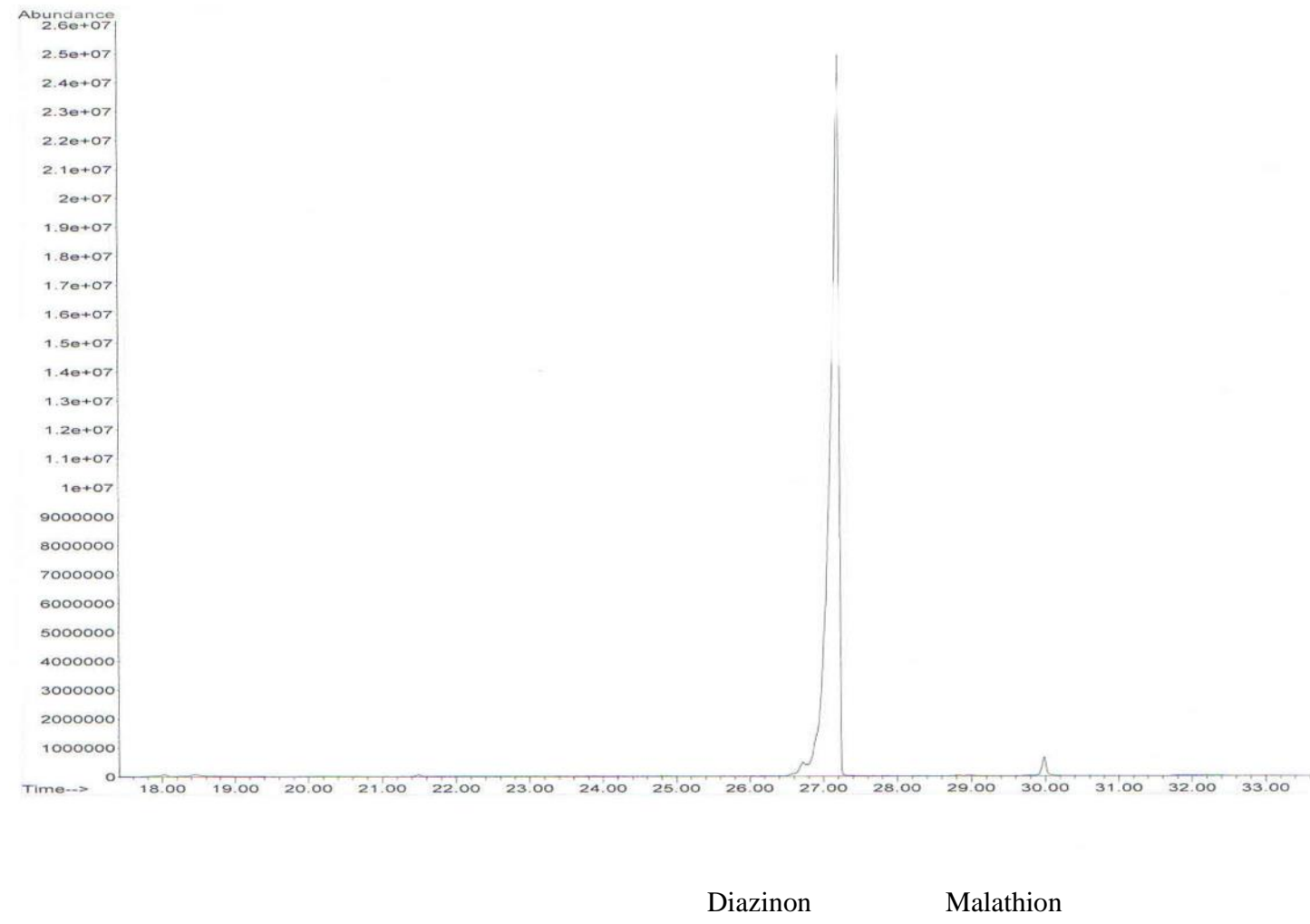

Figure 5: Chromatogram showing the great difference between the concentration of Diazinon and that of Malathion in the bottle content 


\section{UPLC/PDA analysis}

The UPLC chromatograms of the authenticated Diazinon and the organic solvent extracts were shown in figure (5). The extract of stomach content, stomach wall, kidney, liver and the bottle wash showed Diazinon peak at retention time of $3.55 \mathrm{~min}$.

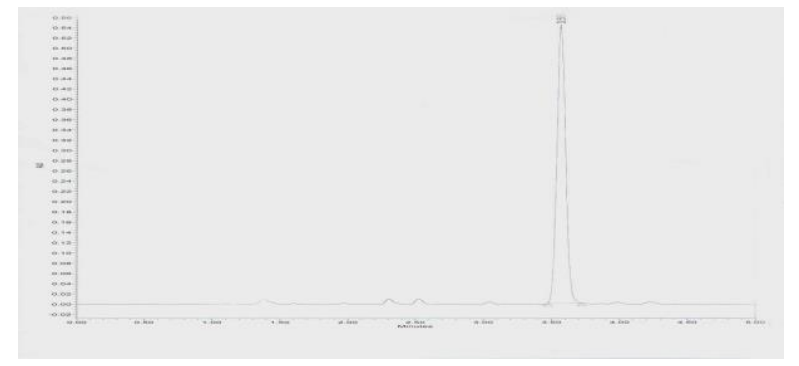

UPLC chromatogram of standard Diazinon using PDA detector.

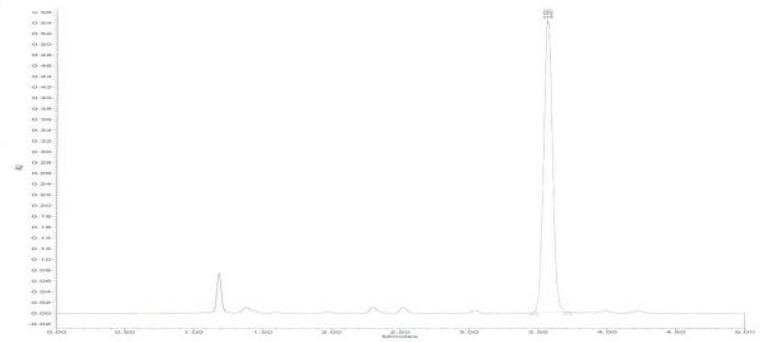

UPLC chromatogram of Diazinon from the bottle wash using PDA detector.

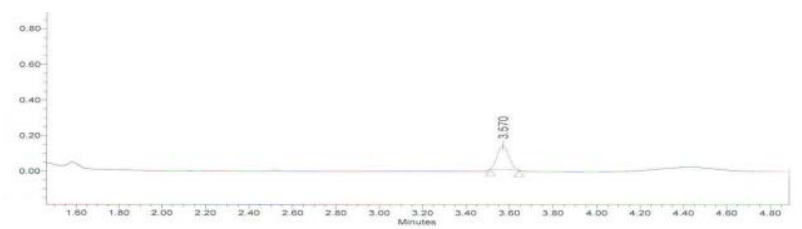

UPLC chromatogram of Diazinon from stomach wall using PDA detector.

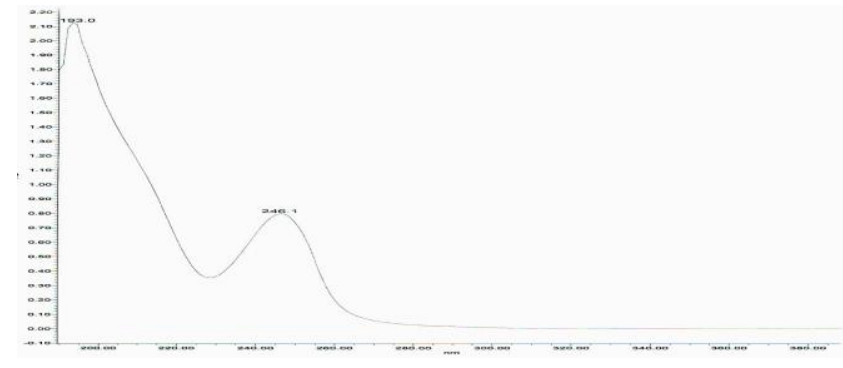

UV-spectrum of Diazinon.

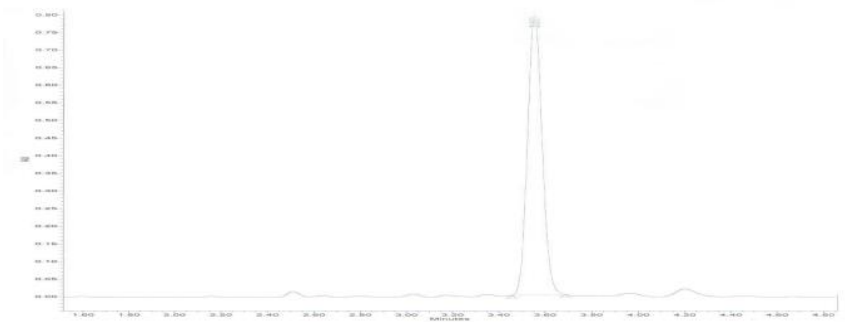

UPLC chromatogram of Diazinon from stomach content using PDA detector.

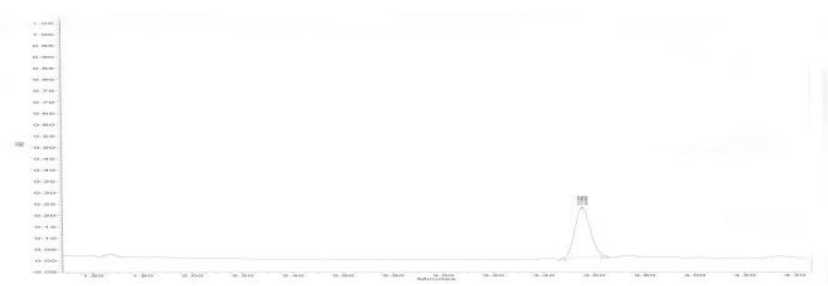

UPLC chromatogram of Diazinon from the liver using PDA detector.

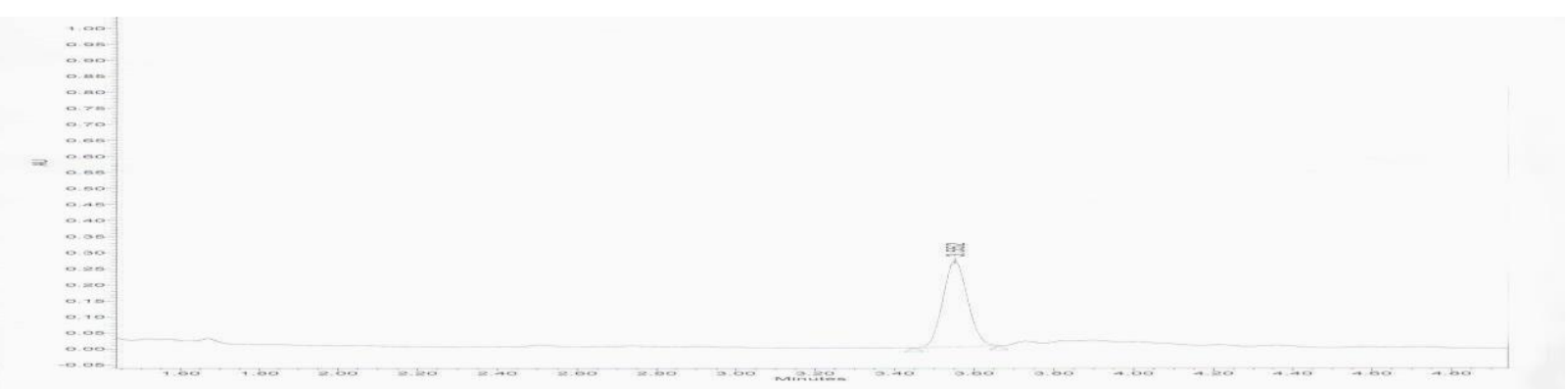

Figure 6: UPLC chromatogram of Diazinon from the kidney using PDA detector. 


\section{Discussion}

We were working on proving that the victim swallowed some of the contents that were in the bottle. It was expected that Diazinon only would be found in the bottle wash and could be found in the stomach content and the other extracts. But Diazinon was detected in the organic extract of the stomach content, stomach wall, kidney sample and liver sample and the bottle wash when analyzed using TLC, GC/MS and UPLC. And in addition to Diazinon, Malathion was detected in the stomach content and the bottle wash. Both Diazinon and Malathion were not detected in the blood extract. Concerning the peaks obtained from GC/MS and UPLC, Diazinon was found in much higher concentration than Malathion. Absence of both pesticides in the blood sample may be attributed to the probability of unsuitable blood biopsy.

\section{Conclusion}

Malathion could be detected with Diazinon due to the non-intended mixing of the pesticides by some farmers during the process of farming. Depending on the great difference between the found concentration of Diazinon and Malathion, it was likely expected that Diazinon was the main cause of death.

Conflict of interest statement: The author declares no conflicts of interest.

\section{References}

1.Li AF, Liu XY, Kong J, Hu HY, Sun LH and Qian Z. Determination of organophosphorous pesticide phosphamidon in environmental water with luminol chemiluminescence detection. J. of AOAC Int. 2009, 92(3):914-918.

2. Taira K, Aoyama Y and Kawamata M. Long QT and ST-T change associated with organophosphate exposure by aerial spray. Env. Tox. Pharm. 2006, 22:40-45.

3. Shigeaki I, Takeshi S, Hiroyasu M, Yosuke S, Kensuke T, Isotoshi $\mathrm{Y}$ and Sadaki I: Rapid simultaneous determination for organophosphorus pesticides in human serum by LC-MS. J. of Pharm. Biom. Analysis 2007, 44:258-264.

4. Gasser R. A new insecticide with a wide range of activity. Zeitschrift für Naturforschung. 1993, 8b: 225-32. International Chemical Safety Cards. 0137. Diazinon. IPCS, 1993.

5.U.S. EPA. 2000. Diazinon: Toxicology chapter for the RED as revised 3/30/00 in response to the Novartis Crop Protection, Inc. responses submitted February 9, 2000 to the RED. Memo from Doherty, J., Health Effects Div., to Chambliss, B., Special Review and Reregistration Div. and Eiden, C., Health Effects Div. Washington, DC. www.epa.gov/pesticides/ op, p. 5.

6. Bianchi-Santamaria, A. Human lymphocyte micronucleus genotoxicity test with mixtures of phytochemicals in environmental concentrations. Mut. Res. 1997, 388:27-32

7. Gordon SM. Residential environmental measurements in the National Human Exposure Assessment Survey (NHEXAS) pilot study in Arizona: preliminary results for pesticides and VOCs. J. Exp. Anal. Environ. Epidemiol. 1999, 9:456-470.

8. Greenman SB. Herbicide/pesticide effects on intestinal epithelial growth. Environ. Res. 1997, 75:85-93

9. Registration Eligibility Decision (RED) Diazinon; EPA 738R-04-006; U.S. Environmental Protection Agency, Office of Prevention, Pesticides and Toxic Substances, Office of Pesticide Programs, U.S. Government Printing Office: Washington, DC, 2006. 